\title{
Article
}

\section{Knowing your click from your clunk [Editorial]}

Perry, D C and Paton, Robin W.

Available at http://clok.uclan.ac.uk/26617/

Perry, D C and Paton, Robin W. (2019) Knowing your click from your clunk [Editorial]. The Bone \& Joint Journal, 101-B (3). pp. 236-237. ISSN 2049-4394

It is advisable to refer to the publisher's version if you intend to cite from the work. http://dx.doi.org/10.1302/0301-620X.101B3.BJJ-2019-0075

For more information about UCLan's research in this area go to http://www.uclan.ac.uk/researchgroups/ and search for <name of research Group>.

For information about Research generally at UCLan please go to http://www.uclan.ac.uk/research/

All outputs in CLoK are protected by Intellectual Property Rights law, including Copyright law. Copyright, IPR and Moral Rights for the works on this site are retained by the individual authors and/or other copyright owners. Terms and conditions for use of this material are defined in the policies page.

\section{CLoK}

Central Lancashire online Knowledge www.clok.uclan.ac.uk

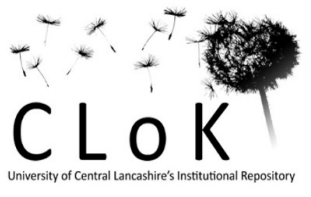




\section{Knowing your click from your clunk: Is current DDH screening fit for purpose?}

In 2000 the journal published an editorial concerning screening in Developmental Dysplasia of the Hip (DDH), based on expert opinions from the UK and Sweden ${ }^{1}$. It considered the effectiveness of clinical examination and ultrasound imaging of the hip in the screening of pathological DDH. The conclusion was that the effectiveness of hip screening policies for the diagnosis and treatment of DDH was unclear. A recent editorial ${ }^{2}$ in a paediatric journal again raised concerns on the efficacy of the current clinical DDH screening programme.

Recently, the Bone and Joint Journal have published long-term observational studies casting doubt on the association of pathological DDH with asymmetrical skin creases, foot abnormalities and 'clicky' hips 3,4,5 each of which have contributed to the selective screening programme. The Newborn Infant Physical Examination (NIPE) committee is currently reviewing the screening guidelines for diagnosing DDH in England ${ }^{6}$.

What has changed since 2000? The Cochrane review of $2013^{7}$ stated that levels of evidence for the effectiveness of screening in DDH are generally poor with no improvement in the numbers of late diagnosed DDH requiring surgery since the introduction of screening with insufficient evidence to give clear recommendations. In 2014, the AAOS ${ }^{8}$ in a systematic review, stated that there was moderate evidence to reject universal ultrasound screening and that there was moderate evidence to undertake an imaging study $<6$ months of age in cases of positive Family History, Breech presentation or history of clinical instability. They noted that of the 4026 papers reviewed only 32 had sufficient evidence or quality to be used as guidance.

What do we know? Between 70 to $90 \%$ of clinically unstable hip joints will stabilise spontaneously between 2 and 4 weeks post-natally ${ }^{9,10}$. There is no agreement on what constitutes pathological DDH either clinically or sonographically. Some research groups consider the majority of Graf Type II hips to be pathological, whilst others consider this to be true in only the more severe types of sonographic abnormality ${ }^{11}$. There is no robust evidence to confirm that the splinting of hip joints in early pathological DDH, is an effective treatment i.e. Pavlik harness ${ }^{1,8}$.

Are there trends appearing? The most effective clinical screening programmes resulting in the lowest rates of late irreducible hip dislocation appear to be delivered by focused clinical screening programmes undertaken by a few welltrained hip screening health professionals. Studies in Scotland and Sweden 12,13 have shown improved outcomes when clinical screening is undertaken by small groups of experienced health care professionals. However, the model used in many other countries, including the other 3 nations of the UK uses a broad group of examiners with variable experience. This suggests that many of the examiners undertaking primary clinical hip screening may be too inexperienced to identify the often subtle clinical signs of hip instability, especially given that positive instability tests (Ortolani \& Barlow manoeuvres ${ }^{9,14}$ ) are relatively rare ${ }^{11}$. 
The significance of 'clicky' hips causes considerable debate ${ }^{4,15}$. The debate almost certainly arises, not because clinicians believe that an innocent click is a true 'risk factor', but because primary referrers do not know, or cannot differentiate between instability and physiological clicking. The true clinical signs associated with pathological DDH appear to be positive Ortolani/Barlow manoeuvres 9,16 and unilateral limitation of hip abduction 16: not isolated 'clicky' hips or asymmetrical skin creases ${ }^{3,4}$.

Universal sonographic screening for DDH has been suggested as a solution, though this is controversial. The delayed open reduction rate appears more favourable (i.e. lower) for universal sonographic screening than clinical screening or selective screening (i.e. targeted sonographic hip screening combined with universal clinical hip assessment 17 though this remains the source of debate ${ }^{7,8}$. However, universal sonographic screening introduces over diagnosis of hip pathology, leading to over treatment that could result in long-term complications such as avascular necrosis of the femoral head ${ }^{1}$. In some studies up to $7.0 \%$ of the population may be treated ${ }^{18}$. This is primarily due to the lack of agreement in what constitutes true clinical or sonographic hip pathology.

What is the present NIPE policy ${ }^{19}$, with possible issues on effectiveness?

1. Neonatal assessment within 48 hours of birth (Ortolani \& Barlow manoeuvres), with sonographic assessment of positive cases. Relies on the skills/experience of current primary clinical hip screeners.

2. 'At risk' sonographic screening of 'at risk' children with either breech presentation or and a strong family history (scan at 4 to 6 weeks). If neonatal hip instability is removed from this group, this screening identifies very few positive cases of pathological DDH, and fewer in males ${ }^{11}$. However there is limited evidence supporting this arm of screening ${ }^{8}$.

3. General Practitioner clinical assessment at 6 weeks of age. The majority of positive Ortolani/Barlow hip instability manoeuvres settle by 4 weeks. Unilateral Limitation of abduction, as a clinical sign, usually develops at $>3$ months of age. The timing of the current examination is likely to have a very low yield and recent studies dispute its effectiveness ${ }^{20}$.

4. Confusing situation on the place of true 'clicky' hips or asymmetrical skin creases and their association with pathological DDH. There is a poor or absent association ${ }^{3,4}$.

There is a risk that the current hip-screening regime for DDH is ineffective. It is accepted that it fails to meet the criteria of an effective screening programme and at best should be regarded as hip surveillance ${ }^{11}$. Any national policy will be a compromise and the NIPE committee is necessarily an Expert Based Consensus model. Recommendations of this committee are based on the current suboptimum DDH screening evidence base. There is no evidence that the NIPE guidelines have reduced the definitive outcome of an irreducible hip dislocation 
requiring surgical intervention. A National study comparing contemporary results with the 1998 MRC study ${ }^{21}$ should be considered to assess the efficacy of NIPE policy, or the national neonatal 'NIPE-Smart' database should be extended to incorporate orthopaedic outcomes to effectively measure the efficacy of the programme.

\section{REFERENCES:}

1. Jones D, Dezateaux C, Danielsson LG, Paton RW, Clegg J, Topic for Debate: At the crossroads -neonatal detection of Developmental Dysplasia of the Hip. J BoneJoint Surg Br 82(2): 160-4, 2000

2. Hall DM, Sowden D, Hip hip: no hurray Arch Dis Child. 2018 Apr 16. pii: archdischild-2018-314813. Doi 10.1136/archdischild-2018-314813

3. Anderton MJ, Hastie GR, Paton RW. The positive predictive value of asymmetrical skin creases in the diagnosis of pathological developmental dysplasia of the hip. Bone Joint J. 2018 May 1; 100-B(5):675-679. doi: 10.1302/0301-620X.100B5.BJJ-2017-0994.R2

4. Nie K, Rymaruk S, Paton RW. Clicky hip alone is not a true risk factor for developmental dysplasia of the hip. Bone Joint J. 2017 Nov; 99-B (11): 15331536.doi: 10.1302/0301-620X.99B11.BJJ-2017-0416.R1

5. Paton RW, Choudry QA, Jugdey R, Hughes S, Is congenital talipes equinovarus a risk factor for pathological dysplasia of the hip? : a 21-year prospective, longitudinal observational study. Bone Joint J. 2014 Nov; 96-B(11):1553-5. doi: 10.1302/0301-620X.96B11.34130.

6. NHS Evidence, Screening, Newborn Infant Physical Examination (NIPE) author Elliman D, www.library.nhs.uk/screening.viewResource.aspx?resID=269073

7. Cochrane review: Screening programmes for developmental dysplasia of the hipin newborn infants. Shorter D, Hong T, Osborn DA, Jan 8(1): 11-54 doi 10.1002/ebch.1891, 2013

8. AAOS Detection and non-operative management of paediatric Developmental Dysplasia of the Hip in infants up to six months of age. Evidence based clinical practice guideline. www.aaos.org/research/guidelines/DDHGuidelineFINALpdf 2014

9. Barlow TG, Early diagnosis and treatment of congenital dislocation of the hip J Bone Joint Surg Br 44(2): 292-301, 1962

10. Gardiner HM, Dunn PM, Controlled trail of immediate splinting versus ultrasonographic surveillance in congenitally dislocatable hips Lancet 336(8730): 1553-6, 1990 
11. Paton RW, Thesis for: PhD, University of Lancaster. uk.bl.ethos.618306 2011

12. Duppe H, Danielsson LG, Screening of neonatal instability and of developmental dislocation of the hip. A survey of 132,601 living newborn infants between 1956 and 1999, J Bone Joint Surg Br 84(6): 878-85, 2002

13. McAllister DA, Morling JR, Fischbacher CM et al Enhanced detection services for developmental dysplasia of the hip in Scottish children 1997-2013, Arch Dis Child10.1136/archdischild-2017-314354, 2018

14. Ortolani M, Un segno poco noto e sua importanza per la diagnosi precoce di prelussazione congenital dell'anca, La Pediatria 145: 129-36, 1937

15. Humphry S, Thompson D, Price et al, The Clicky Hip, Bone Joint J, 100-B (9): $1249-52,2018$

16. Choudry Q, Goyal R, Paton RW. Is limitation of hip abduction a useful sign in the diagnosis of developmental dysplasia of the hip? Arch Dis Child 98(11): 8626,2013

17. Graf R, Hip sonography: 20 years experience and results. Hip Int 17 Suppl. 5: S8-14, 2007

18. Von Kries, Ihme N, Oberle D et al. Effect of ultrasound screening on the rate of first operative procedures for developmental dysplasia in Germany. Lancet 362(9399): 1883-7, 2003

19. Newborn and infant physical examination screening: clinical guidance. www.gov.uk/government/collection/ newborn-and-infant-physicalexaminationscreening-clinical-guidance 2014

20. Davies RM, Mace J, Talbot $C$ et al, Evaluation of the six to 8 week GP check for developmental dysplasia of the hip. Orthopaedic Proceedings Vol98-B Issue Suppl_15 1 September 2016

21. Godward S, Dezateaux C, Surgery of congenital dislocation of the hip in the UK as a measure of outcome of screening. MRC Working Party on Congenital Dislocation of the Hip. Medical Research Council. Lancet 351(9110): 1149-52, 1998 